\title{
PSICANÁLISE E PESQUiSA
}

\author{
Ana Paula Lacorte Gianesi \\ Instituto de Psicologia - USP
}

\begin{abstract}
Este trabalho pretende situar a práxis psicanalítica no terreno da áica. O exercício da psicanálise delimita, por sua própria condição, um campo $e$, neste, o psicanalista se vê incluído como quem está constantemente a pesquisar. Para tornar factível uma trajetória haverá discussão entre o discurso psicanalítico e aquele da ciência. A clínica, lugar que faz esta prática demonstrar-se, a cada vez, a cada novo encontro entre analista e analisante, aparece neste texto com privilegiado destaque.
\end{abstract}

Descritores: Psicanálise. Pesquisa. Ética. Ciência.

\author{
Je suis toujours tourmentée par \\ quelque chose d'absent
}

(Camille Claudel)

\begin{abstract}
Greud (1912/1976), em suas recomendações, deixou escrito: "Uma das 1 reivindicações que a psicanálise faz em seu favor é, indubitavelmente, o fato de que, em sua execução, pesquisa e tratamento coincidem" (p. 152). E Lacan (1966/1998, p. 71) escreveu:
\end{abstract}

... Que se possa ver, no que aqui se desenha de uma referência à linguagem, o fruto da única imprudência que nunca nos enganou: a de não nos fiarmos a nada senão à experiência do sujeito que é a matéria única do trabalho analítico.

1 Metre e Doutoranda em Psicologia Clínica pelo Instituto de Psicologia - USP. Endereço eletrônico: anagi@csbr.com.br 


\section{Ana Paula Lacorte Gianesi}

O recorte que a psicanálise realiza, ao dar lugar ao sujeito do inconsciente, possibilita o exercício de uma prática específica. A pesquisa é, neste âmbito, consubstancial à clínica, dimensão essencial desta última. A proposta explicitada, em princípio por Freud, depois lapidada por Lacan, comporta, certamente, uma subversão e uma inauguração.

A atividade psicanalítica propicia que a subjetividade seja submetida a uma nova experiência, isto porque por meio da psicanálise, "a razão é questionada na sua consciência” (Nogueira, 1997, p. 133).

Com a prática da psicanálise não se está fazendo filosofia. A experiência psicanalítica "é radicalmente exterior e estrangeira à filosofia" (Badiou, 2002, p. 13). Não obstante este fato, o terreno em foco constantemente se situa diante de fundamentos e questões da epistemologia, tomando, assim, a filosofia como interlocutor. Outrossim, não se trata de uma técnica. "A razão técnica, administrada, aplicada está longe de ser compatível com a clínica psicanalítica" (Dunker, 2003, p. 3).

Neste sentido, é interessante acompanhar as construções feitas por Badiou (2002), quando este reafirma o estatuto de antifilosofia concedido por Lacan à psicanálise:

\footnotetext{
A antifilosofia designa a ambigüidade destas duas relações, uma de distância e outra de proximidade (...) Funções que se contrariam e cuja contrariedade lê-se lá onde o prefixo 'anti', função de distância, sustenta também a afirmação da 'filosofia', função de proximidade. (Badiou, 2002, p. 39)
}

Segue-se, então, a localização do campo psicanalítico como uma práxis. Eis aqui mais uma referência à filosofia, aos seus fundamentos. A noção de práxis, tão cara à psicanálise, surge com o esforço de pensamento de $\mathrm{Pla}$ tão e depois de Aristóteles:

Tanto a concepção platônica quanto a aristotélica pressupõem as particularidades semânticas do termo práxis, cuja significação primordial diz respeito de um lado ao ato do sujeito, ao seu realizar-se na ação e pela ação e, de outro, à perfeição ou excelência que o ato tem em si mesmo. (Vaz, 1993, pp. 85-86) 


\section{Psicanálise e Pesquisa}

A construção da lógica da práxis realizada pela filosofia permite e inaugura as reflexões sobre a ética, sobre as relações e adequações "entre os meios, os fins e o agente de uma determinada ação" (Dunker, 1999, p. 58).

A psicanálise, com seu discurso, propõe-se, então, uma ética, "que é a prática de sua teoria" (Nogueira, 1997, p. 133). A práxis psicanalítica é, então, a um só tempo clínica e teórica.

A ética tem "uma preocupação com a Ciência e a produção psicanalítica" (Nogueira, 1997, p. 133). Abrindo uma trilheira na tentativa de se encontrar possíveis ligações entre a ciência e a ética da psicanálise, deparamonos com a indagação de Lacan (1965-1966/1998) sobre a "vocação de ciência da psicanálise" (p. 870).

Introduzimos, por ora, a seguinte interrogação: "O que é uma ciência que inclui a psicanálise?" (Milner, 1996, p. 32).

Elia e Alberti (2000, p. 21), referindo-se a Lacan, dizem que:

... a psicanálise constitui um saber inteiramente derivado porém não integrante do campo científico, porquanto resulta de uma operação de "subversão" desse campo pelo viés do sujeito.

Os fundamentos que esclarecem esse posicionamento relacionam-se ao corte atribuído à ciência moderna, com Galileu e Descartes. A psicanálise tem sua condição de possibilidade apoiada nesta ciência, é derivada da última, porém não se reduz a mesma.

Miller (1999) traz uma importante contribuição para o estudo relativo aos campos discursivos da psicanálise e da ciência:

... a ciência supõe a extinção da significação (...). A ciência supõe a disjunção do simbólico e do imaginário, do significante e da imagem (...) a teoria científica exigiu aferrar-se ao significante enquanto separado de toda significação imaginária (...) a ciência supõe que no mundo existem significantes que já não querem dizer nada para ninguém (...) Há significantes independentemente do sujeito. Há significante organizado segundo leis autônomas que funcionam independentemente da consciência que o sujeito possa ter dele ou da expressão; é o sujeito, justamente, que é um efeito do funcionamento das leis significantes. Por isso Lacan diz, e afinal a história parece confirmá-lo, que a psicanálise não era possível antes do advento do discurso da ciência. 


\section{Ana Paula Lacorte Gianesi}

A ciência é movida pela idéia que há um saber no real. Um saber independente da noção que os sujeitos possam ter a respeito do mundo. Neste sentido, Lacan (1965-1966/1998, p. 878) escreve que o sujeito sobre o qual se opera em psicanálise é o sujeito da ciência.

Entrementes, como anteriormente pontuado, a psicanálise não equivale à ciência moderna. Isto porque esta última, ao fundar-se, introduz o sujeito em sua cena discursiva e, consubstancialmente, o exclui. A psicanálise, com seu método inaugural, reintroduz o sujeito rechaçado pelo agenciamento operacional da ciência, nomeando-o sujeito do inconsciente. O sujeito está implicado no campo psicanalítico, fato que a ciência moderna parece não suportar. Esta cria o sujeito, mas o exclui de seu terreno operatório.

\footnotetext{
Lacan formula - o que lhes pode parecer paradoxal - que o sujeito do inconsciente freudiano, esse sujeito que aparentemente é muito diferente de um cogito, é o sujeito da ciência, é o sujeito pontual e desvanescente de Descartes. Aqui temos que distinguir duas coisas. Em primeiro lugar, esse sujeito da ciência que emerge com Descartes, ao mesmo tempo em que emerge é rechaçado do discurso da ciência, é uma das suas condições, mas uma condição foracluída, rechaçada para o exterior, o que faz com que a ciência se apresente como um discurso sem sujeito... (Miller, 1999)
}

A reintrodução do sujeito no terreno da ciência, realizada pelo discurso psicanalítico, torna viável a assertiva segundo a qual o ato da fala estabelece, sim, a certeza, mas a certeza de que "o sou é um ente marcado pela castração" (Juranville, 1987, p. 128). Deste modo, a psicanálise subverte a fonte que lhe fornece os primeiros goles, postulando que o sujeito do inconsciente, do significante, o falante, aquele assujeitado pela linguagem, que fala a verdade, é desejante. Pensa onde não é, e é onde não pensa.

Lacan (1975/1985, p. 68), diz, então, que o discurso analítico é um novo discurso tomado pela função significante:

"O sujeito não é outra coisa - quer ele tenha ou não consciência de que significante ele é efeito - senão o que desliza numa cadeia de significantes. Este efeito, o sujeito, é o efeito intermediário entre o que caracteriza um significante e outro significante." 
A originalidade do método concebido pela psicanálise aponta a exclusividade do sujeito. O que advém da clínica inaugura sempre um campo irreproduzível, o que se passa entre analista e analisante não está restrito aos limites da consciência, que pede consistência. Há singularidade, cada sujeito do inconsciente não equivale a qualquer outro. Assim, quando se supõe o inconsciente, o qual se revela através de suas manifestações, concebe-se um saber diferente daquele produzido pela reflexão consciente, origem do conhecimento.

Dizer que a psicanálise se volta ao sujeito do inconsciente, bem como que clínica e pesquisa coincidem, faz pensar sobre os fundamentos e a transmissibilidade deste campo. Formulamos, deste modo, outra pergunta: como "transmitir para a cultura as questões que surgem na relação analítica”? (Nogueira, 1997, p. 147).

Na tentativa de fundamentar a psicanálise e responder à interrogação sobre a questão de transmissibilidade desta, Lacan recorre à matematização e à topologia. Ao falar sobre o signo matemático e os matemas, o psicanalista aponta:

... unicamente pelo fato de eles se transmitirem integralmente. Não se sabe absolutamente o que eles querem dizer, mas eles se transmitem. Nem por isso deixa de acontecer que eles só se transmitem com o auxílio da linguagem, é o que constitui toda a claudicação do negócio. (Lacan, 1975/1985, p. 150)

O caráter claudicante da transmissão da psicanálise é apontado, também, por Badiou:

A matematização é, para o discurso analítico, ao mesmo tempo, ideal disponível à transmissão integral e real como impasse da formalização, impasse graças ao qual aquilo que advém do real em uma análise pode e deve coexistir." (Badiou, 2003, p. 37)

A proposição do termo matema indica que este é o símbolo do Real. A transmissão integral que este proporciona é referente àquilo que é próprio do discurso analítico, do discurso do Campo Freudiano. O matema se transmite com o auxílio da linguagem, é certo, diz respeito também ao simbólico, mas afasta-se, ao máximo, da significação imaginária. 


\section{Ana Paula Lacorte Gianesi}

Neste mesmo caminho, Lacan (1969-1970/1992, p. 116) não deixa de enfatizar o fato "indispensável para a vida que alguma coisa irredutível não saiba”. Ele grifa, com isso, a idéia do Real como o impossível.

"A psicanálise não permite saber tudo, pois o inconsciente não diz tudo" (André, 1998, p. 10).

O impossível aparece, então, enquanto termo que impõe limite ao saber. O saber psicanalítico é:

... saber furado, afetado por uma falha central (...) Lacan nos convida a compreender que esta falha não é da ordem de uma imperfeição que os progressos da pesquisa permitiriam preencher, mas sim que ela constitui a chave para a própria estrutura do saber (...) a psicanálise permite saber "não-todo" (André, 1998, p. 10).

Transmitir aquilo que decorre de uma experiência singular com a matéria única do trabalho analítico, o sujeito do inconsciente, tangencia o Real como o impossível. Isso, pois, coloca a questão do objeto que falta e da verdade como causa.

As reflexões iniciadas até este ponto indicam que a estrutura discursiva na qual o psicanalista trabalha se encontra no campo de efeitos da linguagem, mas não se reduz ao significante, nem tudo é significante...

Dizer efeito da linguagem é dizer efeito da estrutura que, de um lado, produz a causa material - o significante -, o significante em sua forma literal, operando separado de sua significação, - e, de outro, engendra um resto, uma perda, algo que lhe é, ao mesmo tempo intrínseco e heterogêneo - o objeto $a$, real, - essa causa que divide o sujeito, causando-o como sujeito de desejo. (Souza, 1996, p. 72)

A linguagem, segundo o que a psicanálise revela, é aquilo que distingue a realidade humana das outras existências, ao surgir e inaugurar o sujeito do inconsciente, funda uma realidade, a realidade propriamente humana. A linguagem é estruturante para o humano, produz efeitos originários desta mesma, não necessitando de nada anterior para justificar seu aparecimento.

Da linguagem surge o sujeito assujeitado por esta mesma. Segundo Lacan (1969-1970/1992, p. 13), existem estruturas, ou relações estáveis que se fixam mediante o instrumento da linguagem. $\mathrm{O}$ aparecimento do sujeito 


\section{Psicanálise e Pesquisa}

se dá através de uma relação fundamental, de um significante, que representa este sujeito para um outro significante, o que, então, distingue o sujeito do indivíduo vivo:

... é no instante mesmo em que $\mathrm{S} 1$ intervém no campo já constituído dos outros significantes, na medida que eles já se articulam entre si como tais, que ao intervir junto a um outro, do sistema, surge isto, $\$$, que é o que chamamos de sujeito como dividido. (Lacan, 1969-1970/1992, p. 13)

E desta operação sobra um resto...

Assim, quando se delimita o espaço da psicanálise enquanto constituído pelos efeitos de linguagem e se afirma que esta última é condição para o trabalho analítico, está se adentrando em um terreno que não é dado de imediato. A linguagem, como acima mencionado, é condição para o inconsciente, uma vez que este é inaugurado por aquela e que é apenas através da linguagem que se tem acesso às manifestações do inconsciente. A linguagem não possibilita, então, o acesso à realidade. Falar sobre a realidade implica em uma distinção em relação à mesma, tornando-a assim, enquanto totalidade, inacessível a qualquer um. Entra-se em contato com a realidade através da linguagem.

Não há realidade pré-discursiva (Lacan, 1975/1985). Não se tem acesso a uma mítica realidade primeira, comumente referida às origens. Substituindo o que seria a coisa em si deste real, opera a linguagem, que cria modelos e os refere ao inacessível original. Não se pode localizar na realidade externa ou temporal, que exige uma data, marcos ou marcas subjetivas.

Nesta direção da fundação de um campo que se distingue dos fatos concretos da realidade e se aproxima dos operadores simbólicos, estruturais, afirma-se que o sujeito está imerso na linguagem. Sem saber exatamente como ou quando, operadores estruturais podem se inserir.

Diz-se, então, que o atributo à origem do sujeito decorre de um modelo que só pode ser utilizado depois do ocorrido, momento impossível de se saber.

Novamente, segundo Lacan (1969-1970/1992, p. 117): 


\section{Ana Paula Lacorte Gianesi}

Se pudermos perceber que a psicanálise nos demonstra que a criança é o pai do homem, certamente deve haver, de algum modo, alguma coisa que faz a mediação, que é precisamente a instância do mestre na medida em que esta chega a produzir, de qualquer significante, afinal, o significante-mestre.

Neste sentido, Nogueira (1997) deixa escrito: "Levando em conta relações de linguagem como um contato mediatizado com a realidade, o inconsciente vai ser tomado como efeito que aparece na nossa linguagem" (Nogueira, 1997, p. 31).

Não se tem acesso ao próprio inconsciente, mas às manifestações do inconsciente. Este não é um objeto a ser estudado pela psicanálise, e sim, um conceito que não pode ser observado e, então, mantém seu status de impossível, mas é indicado a partir daquilo que decorre das relações de linguagem que se dão entre os falantes.

A linguagem produz efeitos que são produzidos pela relação de fala. Entre analista e analisante dá-se uma peculiar relação entre falantes, o que propicia a fundação de um discurso: o discurso do analista.

Em sua atividade, o psicanalista trabalha com as manifestações do inconsciente. Porém, para que tais derivados possam aparecer no trabalho analítico, é necessária uma determinada formação contextual.

O sujeito em análise é suposto em sua hiância e é a partir desta que estabelece uma relação peculiar com o analista, através da qual busca um saber. $\mathrm{O}$ analista também se posiciona diante do campo do sujeito estruturado pela linguagem. Neste sentido, para que o sujeito do inconsciente possa manifestar-se é preciso uma condição específica, montada a partir do método psicanalítico.

Assim, para que a referida situação entre analista e analisante ocorra, faz-se necessário um corte, cuja função é propiciar a emergência da relação transferencial. Nesta relação o analista ocupa uma posição. Ele se coloca em determinada posição e é preciso que seja posto em um lugar pelo analisante. O analista ocupa, de acordo com o analisante, a posição de um saber. Este último atribui ao analista uma condição e um poder, o de conduzi-lo a um saber. O analista, entretanto, evidencia sua inadequação relativa à demanda 


\section{Psicanálise e Pesquisa}

de saber dirigida a ele, assume a posição do objeto $a$, causa do desejo do analisante e é deste lugar que dirige a análise.

Esperar-se-á, também, por estrutura, a transferência.

Segundo Miller (1999, p. 72):

A convicção racionalista de Lacan é de que a transferência não é um milagre diante do qual o psicanalista deve ajoelhar-se. A teoria do sujeito suposto saber situa a transferência como consequiência imediata da estrutura da situação analítica, quer dizer, como conseqüência imediata daquilo que Lacan chamou de discurso analítico; com esse termo, não se refere ao que o analista relata, mas justamente à estrutura da situação analítica (...) A questão aqui reside em se interessar mais pela estrutura da situação analítica, o que os psicanalistas tem uma irresistível propensão a esquecer. A estrutura da situação analítica coloca, em primeiro lugar, o analista em posição de ouvinte, ouvinte do discurso que ele estimula no paciente, posto que o convida a se entregar a ele sem omitir nada, sem consideração pelas conveniências.

A transferência que advém da estrutura psicanalítica surge, na clínica, como instituição da relação peculiar que ocorre entre analista e analisante:

Para Lacan, existe abertura à transferência pelo fato - e é isso o importante- pelo fato único de que o paciente se coloca em posição de se entregar à livre associação. Coloca-se na posição de buscar a verdade sobre si mesmo, sobre sua identidade, sobre seu verdadeiro desejo. Onde busca a verdade? Busca-a, diz Lacan, no limite de sua palavra, e o limite de sua palavra está ai, no analista enquanto grande Outro, ouvinte fundamental que decide a significação.... (Miller, 1999, p. 73)

O analista é, segundo o analisante, um sujeito com um suposto saber sobre seu desejo. É este sujeito suposto saber o pivô da transferência.

Em um primeiro momento, no entanto, como bem lembra Dominique Miller (1989, p. 45), a demanda por análise pode aparecer enquanto pedido de escuta de um saber vindo do mestre:

O sujeito apela a um saber objetivo, a uma capacidade próxima do saber médico, que se reduzirá à soma de conhecimentos que o torna possível. Ele se posiciona assim em relação a um lugar determinado, circunscrito. $\mathrm{O}$ primeiro encontro com $\mathrm{o}$ analista não implica de supetão esse efeito de suspensão do saber. 


\section{Ana Paula Lacorte Gianesi}

O questionamento do sujeito em relação ao saber sobre o inconsciente pode não aparecer em princípio:

Trata-se de operar uma divisão entre o que aparece como uma primeira versão da transferência, fase de alienação significante e de intensa ativação imaginária, e outra versão cujo nó é a questão do desejo atualizado pela própria presença do analista. Já vimos, a transferência opera quando realiza o vazio, pela presença do analista. É nesse ponto que ele leva o sujeito a se fazer a pergunta de seu desejo, isto é, a do Outro. (Miller, 1989, p. 45)

O silêncio do analista e sua posição suspensa (objeto $a$ ) diante do analisante são fundamentais, também, para que haja mudança na demanda por análise, transformação do sintoma queixa em sintoma analítico. Para que o sujeito possa deslocar-se de seu pedido por respostas advindo de suas eluc ubrações e certezas imaginárias para questões sobre seu desejo, é preciso suportar a falta ali fundada no vazio que abre o analista.

A autora citada faz outra suposição interessante em relação a este primeiro momento, que requer o saber do mestre:

É sem dúvida paradoxal que, ao formular uma demanda de análise, o sujeito venha apelar a um saber absoluto, para evitar fazer de fato sua pergunta e assim cobrir a verdade com uma tela... (Miller, 1989, p. 46)

Lacan (1958/1998) deixa escrito que com uma oferta ele criara a demanda. Com a oferta: fale tudo o que lhe vier à mente, o analista cria uma demanda de saber e amor, na qual, ele, analista, está incluído como destinatário. A transferência indica um corte, um giro no discurso, a entrada em análise.

A transferência ocorre quando, para o analisante, o suposto saber encarna na figura do analista. Há transferênc ia de saber: "Trata-se de uma ilusão na qual o sujeito acredita que sua verdade encontra-se já dada no analista e que este a conhece de antemão" (Quinet, 2002, p. 26).

Não obstante o movimento do analisante, o analista de forma alguma pode identificar-se com esta posição. A transferência é função do analisante, o analista apenas a utiliza na direção da análise. 


\section{Psicanálise e Pesquisa}

"A posição do analista não é a de saber, nem tampouco a de compreender o paciente, pois se há algo que deve saber é que a comunicação é baseada no mal-entendido" (Quinet, 2002, p. 26).

Dentro, ainda, do campo original que a psicanálise inaugura para se investigar a condição humana, outros elementos da estrutura devem ser abordados: a associação-livre, enquanto regra fundamental e a escuta analítica. Ao convidar o analisante a associar livremente, o analista permanece atento à fala deste outro, privilegiando as manifestações mesmas da língua.

Na sequiência da associação-livre dos analisantes, os psicanalistas não se atêm aos sentidos convencionais propostos pelas estruturas formais de comunicação:

Qualquer substituição entre significantes, na acepção lacaniana, produz sentido. Isto mostra que Lacan não trabalha com os mesmos significantes do código lingüístico, que compõem uma espécie de fichário de representações pré-fabricadas, mas com aqueles do sonho e do sintoma, muitas vezes imprevisíveis ou nãocodificáveis, com os quais tudo pode enviar a tudo. (Peixoto, 1999, p. 159)

O sujeito da psicanálise é desprovido de mestria em relação à linguagem que nele fala. Na experiência analítica, ocorre o posicionamento deste sujeito que passa a questionar um saber sobre o inconsciente, que está sendo investigado pelo método, pela operação analítica. Ao ser escuta do discurso do outro, o analista deixa em suspenso seu próprio discurso. As palavras são do analisante. As palavras são livremente dadas ao analisante...

Ao analisante é solicitado:

... que abandone qualquer referência que não seja a das quatro paredes que o envolvem, e que produza significantes que constituam a associação livre soberana, em suma, do campo (...) Dizer qualquer coisa, como é que isto poderia levar a algo, se já não estivesse determinado que, no surgimento ao acaso dos significantes - pelo próprio fato de tratar-se de significantes - não há nada que não se reporte àquele saber que não se sabe, que na verdade é o que trabalha? (Lacan, 1969-1970/1992, p. 32)

A psicanálise trabalha, portanto, com a hipótese do inconsciente e supõe um sujeito atravessado pelos efeitos da linguagem, sujeito causado pela 
verdade que é "a causa presentificada na forma do acidente, a causa como tropeço, mancada, traumatismo inassimilável” (Souza, 1996, p. 69). Enfim, é a este sujeito que suporta, por sua própria condição, "qualquer coisa de ausente", que a clínica psicanalítica volta sua atenção e, como uma práxis que é, não cessa de fazer pesquisa...

Gianesi, A. P. L. (2004). Psychoanalysis and research. Psicologia USP, $15(1 / 2), 169-182$.

Abstract: This work seeks to approximate psychoanalytic praxis to the ethics field. The practice of psychoanalysis sets up a condition in which the psychoanalyst is constantly conducting a particular kind of research. The setting of this research is the clinics of psychoanalysis, which is explored throughout this article.

Index terms: Psychoanalysis. Research. Ethics. Science.

Gianesi, A. P. L. (2004). Psychanalise Et Recherches. Psicologia USP, $15(1 / 2), 169-182$.

Résumé: Ce travail a pour but situer la praxis psychanalitique dans le domaine de l'éthique. L'exercice de la psychanalyse délimite, à son ordinaire, un champ où se trouve le psychanaliste, qui recherche constamment. Pour rendre possible un trajet, il y aura une discussion entre le discours psychanalitique et celui de la science. La clinique, endroit où cette pratique a toujours lieu, chaque fois, à chaque entretien entre analyste et patient, est en évidence dans ce texte

Mots-clés: Psychanalyse. Recherche. Ethique. Science. 


\section{Psicanálise e Pesquisa}

\section{Referências}

André, S. (1999). O que quer uma mulher? Rio de Janeiro: Jorge Zahar.

Badiou, A. (2002). Lacan e Platão: O matema é uma idéia? In: V. Safatle, Um limite tenso: Lacan entre a filosofia e a psicanálise. São Paulo: Editora da Unesp.

Dunker, C. I. H. (1999). Crítica da ideologia estética em psicanálise: Um estudo sobre o fim de análise. In I. Carone. (Org.), Psicanálise fim de século: Ensaios críticos. São Paulo: Hacker.

Dunker, C. I. H. (2003). Lógica e política da constituição do sujeito - Sobre a possibilidade de formalização da clínica psicanalítica. Projeto de Pesquisa aprovado pela Coorpesq - Unimarco.

Elia, L., \& Alberti, S. (2000). Clínica e pesquisa em psicanálise. Rio de Janeiro: Rios Ambiciosos.

Freud, S. (1976). Recomendações aos médicos que exercem a psicanálise. In S. Freud, Edição standard brasileira das obras psicológicas completas de Sigmund Freud (Vol. 12). Rio de Janeiro: Imago. (Trabalho original publicado em 1912)

Juranville, A. (1987). Lacan e a filosofia. Rio de Janeiro: Jorge Zahar.

Lacan, J. (1985). O Seminário. Livro 20: Mais ainda. Rio de Janeiro: Jorge Zahar. (Trabalho original publicado em 1975)

Lacan, J. (1992). O Seminário. Livro 17: O avesso da psicanálise. Rio de Janeiro: Jorge Zahar. (Trabalho original publicado em 1969-1970)

Lacan, J. (1998). A direção do tratamento e os princípios de seu poder. In J. Lacan, Escritos (pp. 591-653). Rio de Janeiro: Jorge Zahar. (Trabalho original publicado em 1958)

Lacan, J. (1998). Ciência e verdade. In J. Lacan, Escritos (pp. 869-892). Rio de Janeiro: Jorge Zahar. (Trabalho original publicado em 1965-1966)

Lacan, J. (1998). De nossos antecedentes. In J. Lacan, Escritos (pp. 69-76). Rio de Janeiro: Jorge Zahar. (Trabalho original publicado em 1966)

Miller, D. (1989). As três transferências. In Clínica Lacaniana: Casos clínicos do campo freudiano (pp. 44-50). Rio de Janeiro: Jorge Zahar.

Milner, J.-C. (1996). A obra clara: Lacan, a ciência, a filosofia. Rio de Janeiro: Jorge Zahar.

Miller, J.-A. (1999). Percurso de Lacan - Uma Introdução. Rio de Janeiro: Jorge Zahar. 


\section{Ana Paula Lacorte Gianesi}

Nogueira, L. C. (1997). A psicanálise: Uma experiência original o tempo de Lacan e a nova ciência. Tese de Livre-docência, Instituto de Psicologia, Universidade de São Paulo, São Paulo.

Peixoto Junior, C. A. (1999). Metamorfose entre o sexual e o social: Uma leitura da teoria psicanalítica sobre a perversão. Rio de Janeiro: Civilização Brasileira.

Quinet, A. (2002). As $4+1$ condições da análise. Rio de Janeiro: Jorge Zahar.

Souza, N. S. (1996). O conceito de causa em Lacan In A. B. Freire, F. L. Fernandes \& N. S. A. Souza, A ciência e a verdade - Um comentário. Rio de Janeiro: Revinter.

Vaz, H. C. de L. (1993). Escritos de filosofia II: Ética e cultura. São Paulo: Loyola.

Recebido em 09.06.2004 Aceito em 06.08.2004 